\title{
Assessment of laparoscopic colectomy as the standard treatment of cancer colon
}

\author{
Emad Abdelateef, MD; Ahmed Kamal, MD; Hamed Abo Steit, MD; \\ Hisham Omran, MD; Ahmed Elnabil, MD; Haitham Elmaleh, MRCS, MD \\ Department of General Surgery, Ain Shams University, Cairo, Egypt.
}

Background \& objectives: Laparoscopic colectomy had become a popular choice for treatment of cancer colon, as it is feasible, safe and provides many advantages to the patients in comparison to open colectomy. However, the adoption of the technique as the routine treatment for patients with cancer colon is still a subject of clinical trials.

Methods: 60 patients with cancer colon were randomly divided into 2 equal groups. Group A patients underwent open surgery, and group B patients had laparoscopic surgery.The results of both groups were compared and statistically analyzed to identify the advantage and limitations of the laparoscopic approach.

Results: Laparoscopic colectomy was associated with longer operative times than open colectomy. The outcomes of patients of the laparoscopic group was comparable (oncological results \& recovery of bowel functions) or better (postoperative pain, wound complications and hospital stay) than the open group.

Conclusions: Laparoscopic resection for cancer colon is safe, feasible and has better recovery and comparable oncological results than open colectomy. More analysis is needed before implementation of the technique in routine practice and training.

\section{Introduction:}

Colorectal cancer is the second leading cause of death from malignancy in the industrialized world, accounting for more than 10 per cent of all cancer deaths. ${ }^{1}$ The only curative treatment is operative excision. Traditionally, this has involved open surgery (OS) and complete resection of the primary tumor; however, since 1991 laparoscopic surgery (LS) has also been used in this context. $^{2,3}$ Several studies have reported the short-term advantages of LS over OS in the treatment of colorectal cancer, such as reduced blood loss, a reduction in pain, more rapid recovery of bowel function, shorter hospital stay and better cosmetic results. ${ }^{4-6}$ Other clinical trials emphasized the improved long-term survival. This had led to a general agreement on laparoscopic surgery as an alternative to conventional open surgery for colon cancer. $2,7-9$
However, despite the theoretical advantages of laparoscopic surgery, it is still not considered the standard treatment for colorectal cancer patients due to technical limitations or characteristics of the patients that may affect short and long-term outcomes. ${ }^{10}$

The aim of this study is to evaluate the utilization of laparoscopic surgery as the standard treatment for elective cases of cancer colon.

\section{Methods:}

The study was carried out in Ain Shams University Hospitals during the period between August 2011 and October 2013. It was a prospective randomized study in which patients referred to our department and diagnosed as resectable cancer colon on elective base were included in the study. The study excluded patients who werenotcandidate 
for laparoscopic approach as patients with extensive intraperitoneal adhesions (previous extensive abdominal surgery or previous attacks of generalized peritonitis) and patients with contraindications for insufflation (sever restrictive pulmonary diseases). The patients were assigned randomly to either Group A (will be operated upon using open approach), or Group B (will be operated upon using laparoscopic approach).

Preoperative preparation of all patients included complete clinical evaluation (history taking and physical examination including per rectal examination (PR), Routine laboratory investigations (CBC, coagulation profile, serum electrolytes, blood sugar level, renal and liver functions), Tumor markers (carcino-embryonic antigen (CEA) \& Cancer Antigen (CA19.9)), ECG, Chest x-ray, Pelviabdominal CT with contrast and colonoscopy with tissue biopsy. All patients were prepared preoperatively with prophylactic parenteral broad-spectrum antibiotics. Prophylactic measures against venous thrombosis were taken. Standard mechanical cathartic bowel preparation 2 days prior to surgery was done only in left sided or rectal tumor.

All the patients were operated on by the same surgical team. The goal of the operation in either group was to achieve radical resection with proper lymphadenectomy, so the same oncological principles were applied in both laparoscopic and open approaches. In both groups, lesions of the ascending colon were treated by Rt. Hemicolectomy, lesions of the hepatic flexure were treated by extended Rt. Hemicolectomy, lesions of the splenic flexure were treated by Lt. hemicolectomy without resection of the sigmoid colon, and lesions of the distal descending or sigmoid colon were treated by Lt. hemicolectomy with resection of the sigmoid colon. Also, in both groups ligation of the vascular pedicle was done as close as possible to their origins to achieve proper nodal dissection.

The procedure was performed with the patients under general anesthesia with endotracheal intubation. A nasogastric tube was inserted to decompress the stomach and a Foley's catheter was inserted to the bladder.
The patient was put in the supine position with a $20^{\circ}$ head-up tilt (reversed Trendelenburg position).

In group B (laparoscopic group): A-For Rt. or extended Rt. hemicolectomy: The surgeon on the left side of the patient with the $1^{\text {st }}$ assistant on his left and the 2nd assistant on the opposite side of the patient. After establishment of pneumoperitonium and insertion of the ports Figure (1a), thorough exploration of the abdominal cavity was done. The omentum was lifted to the upper part of the abdomen. Key steps of the procedure involved (1) Identification of Iliocolic pedicle and division after ligation using clips, (2) Medial dissection ventral to the superior mesenteric vessels and lateral to the duodenum was done up to the transverse colon, (3) Mobilization of the hepatic flexure, (4) Lateral dissection of the ascending colon (dissection was done mainly by the LigaSure $10 \mathrm{~mm}$ instrument), (5) Resection of the colon and small intestine using a linear stapler (Endo GIA), (6) Extraction of specimen through an enlargement of the camera port incision, (7) Extracorporeal iliotransverse anastomosis, (8) Insertion of a drain, (9) Closure of the extraction incision and port sites.

B- For Lt hemicolectomy: The surgeon stod on the rt. side of the patient with the $1^{\text {st }}$ assistant on his left and the $2^{\text {nd }}$ assistant on the opposite side of the patient. After establishment of pneumoperitonium and insertion of the ports Figure (2a), thorough exploration of the abdomen was done. Key steps of the procedure involved (1) Medial dissection under inferior mesenteric vein (IMV) up to the level of transvers colon, then the vein was clipped and divided (2) Dissection of inferior mesenteric artery, then it was clipped and divided (3) Mobilization of the splenic flexure, (4) Division of gastro colic ligament, (5) Lateral dissection of the descending colon (and sigmoid if needed) (dissection was done mainly by the LigaSure $10 \mathrm{~mm}$ instrument), (6) Resection of the colon using a linear stapler (EndoGIA), (7) Extraction of specimen through a left iliac or suprapubic incision, (8) Extracorporeal iliotransverse anastomosis and in cases of 


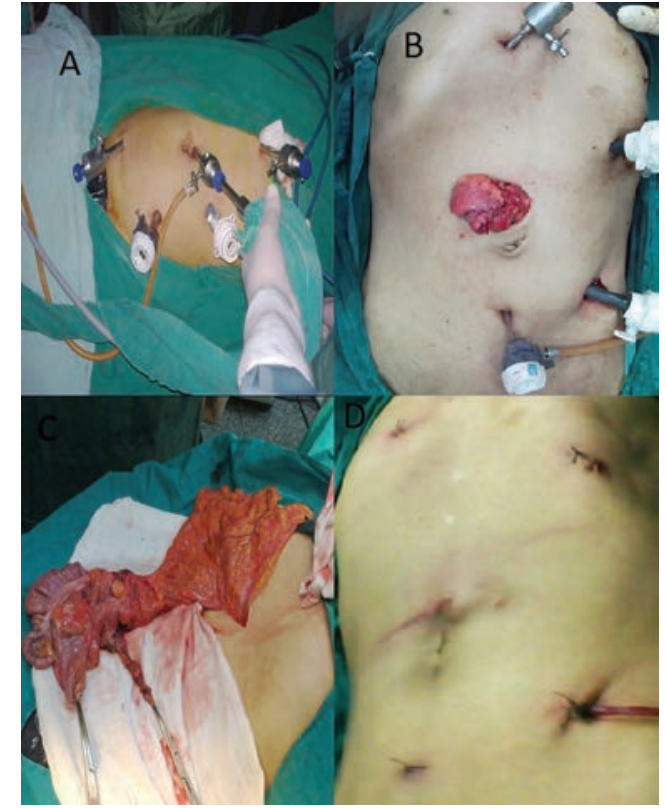

Figure (1): Rt. Hemicolectomy: a-port sites, $b$ - extraction incision, $c$ - extracted specimen. $d$ - after closure of the port sites.
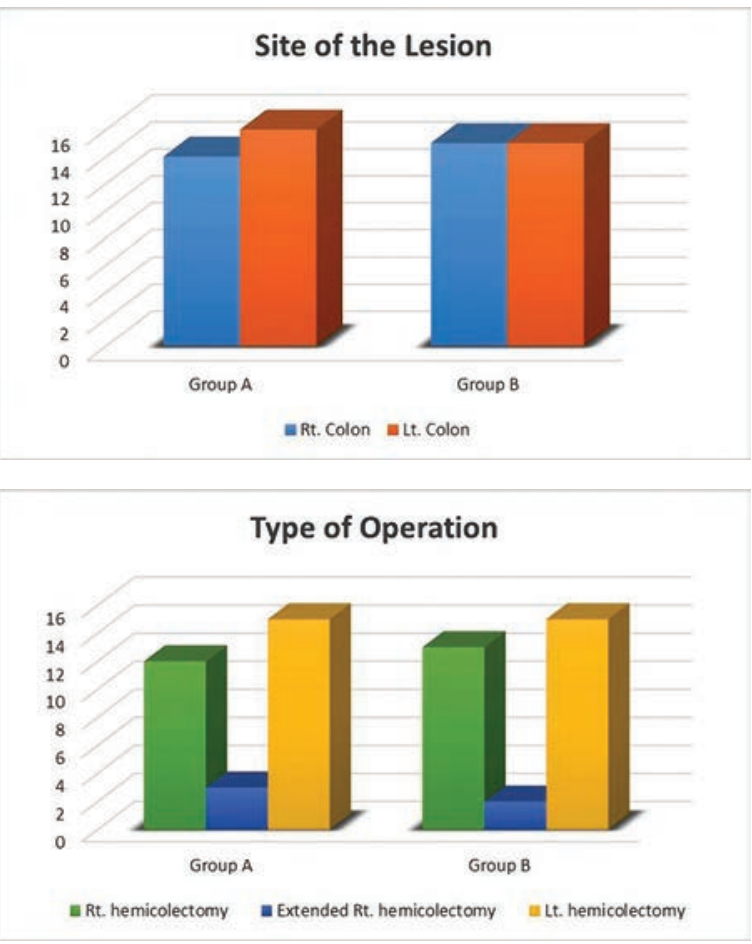

Figures $(3,4)$ : The distribution of the site of lesion and operative management in the study group.

sigmoid resection it was done by circular stapler, (9) Insertion of a drain, (10) Closure of the extraction incision and port sites.

In group A(open group): It. hemicolectomy,

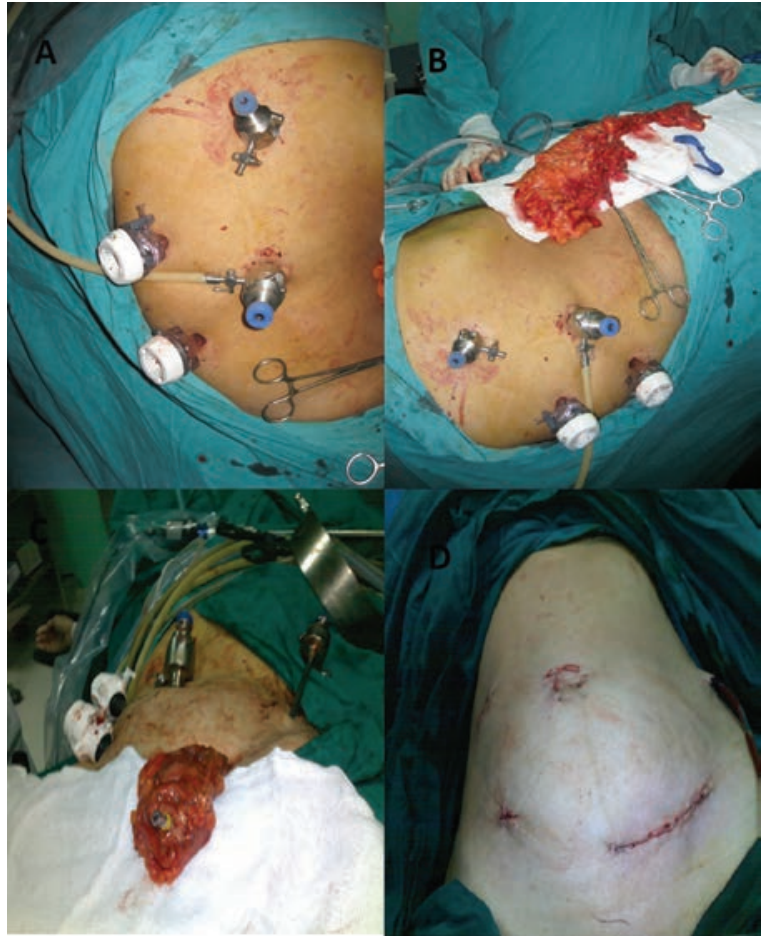

Figure (2): Lt. Hemicolectomy: $a$ - port sites, $b$ \& $c$ - extraction incision \& extracted specimen. $d$-after closure of the port sites.
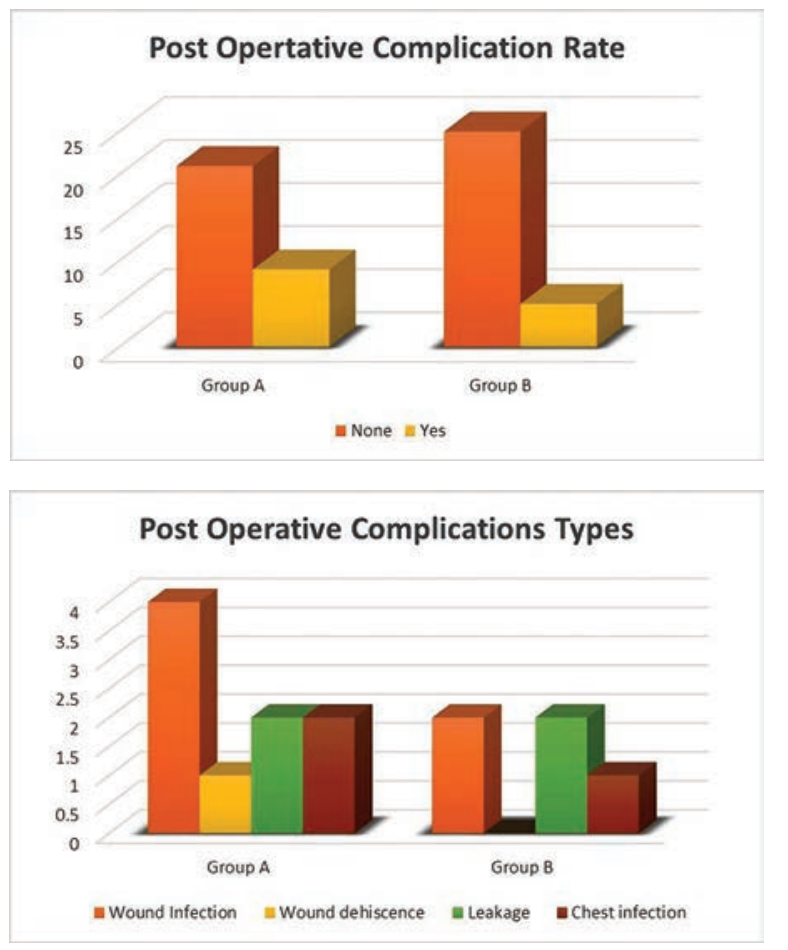

Figures (5,6): The rate and types of postoperative complications in the study group.

rt. or extended rt. hemicolectomy were done according to the standard technique.

Postoperatively, the patients were observed for vital data, need of analgesia, return of 
Table (1): Showing the preoperative characteristics of the study group.

\begin{tabular}{|c|c|c|c|c|c|c|c|c|c|c|}
\hline \multirow{2}{*}{ Variable } & \multirow{2}{*}{ №. } & \multicolumn{2}{|c|}{ Gender } & \multicolumn{3}{|c|}{ Comorbidity } & \multicolumn{2}{|c|}{ ASA score } & \multicolumn{2}{|c|}{ Site of lesion } \\
\hline & & Male & Female & None & DM & HTN & 2 & 3 & Right & Left \\
\hline Group A & 30 & $\begin{array}{l}19 \\
(63.3 \%) \\
\end{array}$ & $\begin{array}{l}11 \\
(36.7 \%) \\
\end{array}$ & $\begin{array}{l}8 \\
(26.7 \%) \\
\end{array}$ & \begin{tabular}{|l|}
10 \\
$(33.3 \%)$ \\
\end{tabular} & $12(40 \%)$ & \begin{tabular}{|l}
20 \\
$(66.7 \%)$ \\
\end{tabular} & \begin{tabular}{|l|}
10 \\
$(33.3 \%)$ \\
\end{tabular} & \begin{tabular}{|l|}
14 \\
$(46.7 \%)$ \\
\end{tabular} & $\begin{array}{l}16 \\
(53.3 \%) \\
\end{array}$ \\
\hline Group B & 30 & $\begin{array}{l}18 \\
(60 \%) \\
\end{array}$ & $\begin{array}{l}12 \\
(40 \%) \\
\end{array}$ & $\begin{array}{l}10 \\
(33.3 \%) \\
\end{array}$ & $9(30 \%)$ & 11 (36.7) & $\begin{array}{l}22 \\
(73.3 \%) \\
\end{array}$ & \begin{tabular}{|l|}
8 \\
$(26.7 \%)$ \\
\end{tabular} & $15(50 \%)$ & $\begin{array}{l}15 \\
(50 \%) \\
\end{array}$ \\
\hline Total & 60 & $\begin{array}{l}37 \\
(61.7 \%)\end{array}$ & $\begin{array}{l}23 \\
(38.3) \\
\end{array}$ & $\begin{array}{l}18 \\
(30 \%) \\
\end{array}$ & $\begin{array}{l}19 \\
(31.7)\end{array}$ & $\begin{array}{l}23 \\
(38.3 \%)\end{array}$ & $\begin{array}{l}42 \\
(70 \%) \\
\end{array}$ & $\begin{array}{l}18 \\
(30 \%) \\
\end{array}$ & $\begin{array}{l}29 \\
(48.3 \%)\end{array}$ & $\begin{array}{l}31 \\
(51.7 \%)\end{array}$ \\
\hline$P$ value & & $>0.05(\mathrm{~N}$ & & $>0.05(\mathrm{~N}$ & & & $>0.05(\mathrm{~N}$ & & $>0.05(\mathrm{~N}$ & \\
\hline \multirow{2}{*}{\multicolumn{3}{|c|}{$\begin{array}{l}\text { Variable } \\
\text { Group A }\end{array}$}} & \multicolumn{4}{|c|}{ Age } & \multicolumn{4}{|c|}{ BMI } \\
\hline & & & \multicolumn{2}{|c|}{ Group B } & \multicolumn{2}{|c|}{ Group A } & \multicolumn{2}{|c|}{ Group A } & \multicolumn{2}{|c|}{ Group B } \\
\hline \multicolumn{3}{|l|}{ Mean } & \multicolumn{2}{|l|}{53} & \multicolumn{2}{|l|}{50} & \multicolumn{2}{|l|}{24} & \multicolumn{2}{|l|}{25} \\
\hline \multicolumn{3}{|c|}{ Std. Deviation } & \multicolumn{2}{|l|}{19} & \multicolumn{2}{|l|}{12} & \multicolumn{2}{|l|}{1.9} & \multicolumn{2}{|l|}{2.3} \\
\hline \multicolumn{3}{|l|}{ Minimum } & \multicolumn{2}{|l|}{30} & \multicolumn{2}{|l|}{26} & \multicolumn{2}{|l|}{21} & \multicolumn{2}{|l|}{20} \\
\hline \multicolumn{3}{|l|}{ Maximum } & \multicolumn{2}{|l|}{62} & \multicolumn{2}{|l|}{58} & \multicolumn{2}{|l|}{28} & \multicolumn{2}{|l|}{30} \\
\hline \multicolumn{3}{|l|}{ P value } & \multicolumn{4}{|c|}{$>0.05$ (NS) } & \multicolumn{4}{|c|}{$>0.05$ (NS) } \\
\hline
\end{tabular}

DM: Diabetes mellitus, HTN: Hypertension, S: Significant, HS: Highly Significant, NS: None Significant.

Tables (2\&3): The type of operative management and the results of intraoperative parameters for each group.

\begin{tabular}{|l|l|l|l|l|}
\hline Variable & $\begin{array}{l}\text { Rt. } \\
\text { hemicolectomy }\end{array}$ & $\begin{array}{l}\text { Extended Rt. } \\
\text { hemicolectomy }\end{array}$ & Lt. hemicolectomy \\
\hline Group A & $12(40 \%)$ & $3(10 \%)$ & $15(50 \%)$ \\
\hline Group B & $13(43.3 \%)$ & $2(6.7 \%)$ & $15(50 \%)$ \\
\hline \multirow{2}{*}{ Variable } & Operative time(min) & Intraoperative blood loss (ml) \\
\cline { 2 - 5 } & Group A & Group B & Group A & Group B \\
\hline Mean & 156 & 222 & 392 & 370 \\
\hline Std. Deviation & 49 & 90 & 96 & 143 \\
\hline Minimum & 78 & 136 & 180 & 200 \\
\hline Maximum & 256 & 318 & 700 & 650 \\
\hline P value & $<0.05(\mathrm{~S})$ & \multicolumn{5}{l}{$>0.05(\mathrm{NS})$} \\
\hline
\end{tabular}

\begin{tabular}{|l|l|l|l|l|}
\hline \multirow{2}{*}{$\begin{array}{l}\text { Amount of transfusion } \\
\text { units) }\end{array}$} & Group A & Group B \\
\cline { 2 - 5 } & Frequency & Percent & Frequency & Percent \\
\hline No & 16 & 53.3 & 17 & 56.7 \\
\hline 1 & 8 & 26.7 & 7 & 23.3 \\
\hline 2 & 4 & 13.3 & 5 & 16.7 \\
\hline 3 & 2 & 6.7 & 1 & 3.3 \\
\hline Total & 30 & 100 & 30 & 100 \\
\hline P value & $>0.05(\mathrm{NS})$ & \multicolumn{4}{l}{} \\
\hline
\end{tabular}


Tables (4): Showing postoperative data.

\begin{tabular}{|c|c|c|c|c|c|c|c|c|c|c|}
\hline \multirow{2}{*}{\multicolumn{3}{|c|}{\begin{tabular}{|l|} 
Type of complication \\
\end{tabular}}} & \multicolumn{3}{|c|}{ Group A } & Group B & \multirow{2}{*}{\multicolumn{2}{|c|}{ Percent }} & P value & \\
\hline & & & \multicolumn{2}{|c|}{ Frequency } & Percent & Frequency & & \begin{tabular}{l|l} 
ent & \\
\end{tabular} & & \\
\hline \multicolumn{3}{|l|}{ None } & 21 & \multicolumn{2}{|c|}{70} & 25 & \multicolumn{2}{|c|}{83.3} & $<0.05(\mathrm{~S})$ & \\
\hline \multicolumn{3}{|c|}{$\begin{array}{l}\text { Overall } \\
\text { complications }\end{array}$} & 9 & \multicolumn{2}{|l|}{30} & 5 & \multicolumn{2}{|l|}{16.7} & & \\
\hline \multicolumn{3}{|c|}{ Wound Infection } & 4 & \multicolumn{2}{|c|}{13.3} & 2 & 6.7 & \multicolumn{2}{|c|}{$<0.01(\mathrm{HS})$} & \\
\hline \multicolumn{3}{|c|}{ Wound dehiscence } & 1 & \multicolumn{2}{|c|}{3.3} & 0 & 0 & \multicolumn{2}{|c|}{+2} & \\
\hline \multicolumn{3}{|c|}{ Leakage } & \multicolumn{2}{|l|}{2} & 6.7 & 2 & 6.7 & $>0$ & $.05(\mathrm{NS})$ & \\
\hline Chest i & fection & & 2 & 6.7 & 1 & & 3.3 & & $.05(\mathrm{NS})$ & \\
\hline Recurr & nce & & 0 & 0 & 0 & & 0 & & $.05(\mathrm{NS})$ & \\
\hline Total & & & 30 & 100 & & 30 & 100 & & & \\
\hline Variable & $\begin{array}{l}\text { Peric } \\
\text { ileus( }\end{array}$ & $\begin{array}{l}\text { d of } \\
\text { days) }\end{array}$ & $\begin{array}{r}\text { Full } \\
\text { intake }\end{array}$ & $\begin{array}{l}\text { oral } \\
\text { (days) }\end{array}$ & $\begin{array}{l}\text { Hos } \\
\text { stayl }\end{array}$ & $\begin{array}{l}\text { spital } \\
\text { (days) }\end{array}$ & $\begin{array}{l}\text { Nee } \\
\text { pare } \\
\text { anal } \\
\text { (da }\end{array}$ & $\begin{array}{l}\mathrm{d} \text { for } \\
\text { nteral } \\
\text { gesia } \\
\text { ys) }\end{array}$ & $\begin{array}{l}\text { LNs ha } \\
\text { (num }\end{array}$ & $\begin{array}{l}\text { arvested } \\
\text { nber) }\end{array}$ \\
\hline & $\begin{array}{c}\text { Group } \\
\text { A }\end{array}$ & $\begin{array}{c}\text { Group } \\
\text { B }\end{array}$ & $\begin{array}{c}\text { Group } \\
\text { A }\end{array}$ & $\begin{array}{c}\text { Group } \\
\text { B }\end{array}$ & $\begin{array}{c}\text { Group } \\
\text { A }\end{array}$ & \begin{tabular}{|c|} 
Group \\
$\mathrm{B}$
\end{tabular} & $\begin{array}{c}\text { Group } \\
\text { A }\end{array}$ & $\begin{array}{c}\text { Group } \\
\text { B }\end{array}$ & $\begin{array}{c}\text { Group } \\
\text { A }\end{array}$ & $\begin{array}{c}\text { Group } \\
\text { B }\end{array}$ \\
\hline Mean & 2.6 & 2.1 & 3.9 & 3.2 & 9.6 & \begin{tabular}{|l|l}
7.1 \\
\end{tabular} & 3.5 & 2.3 & 12.6 & 11.1 \\
\hline Std. Deviation & 0.7 & 0.9 & 1.6 & 1.1 & 1.8 & 0.5 & 0.8 & 0.5 & 0.7 & 0.9 \\
\hline Minimum & 2 & 2 & 3 & 3 & 5 & 5 & 3 & 2 & 8 & 7 \\
\hline Maximum & 6 & 5 & 8 & 7 & 15 & 9 & 7 & 5 & 26 & 25 \\
\hline P value & $>0.05(1$ & NS) & $>0.05$ & NS) & $<0.01$ & (HS) & $<0.05$ & & $>0.05(\mathrm{~N}$ & \\
\hline
\end{tabular}

bowel functions and wound complications. The patients were discharged after return of normal bowel functions, drain removed and any complication ruled out. The patients had follow up visits 1 week after discharge, one month and three months later. The oncological results were assessed by pathological examination of reception margins, number of harvested lymph nodes and any evidence of recurrence after 3 months using contrast enhanced CT scan of the abdomen and pelvis.

Analysis of data was done by SPSS (statistical program for social science version 21) as follows: Description of qualitative variables as number and percentage and quantitative ones as means \pm standard deviation. Chi-square test was used to compare the groups as regard qualitative variable. Fisher exact probability test was used instead of chi-square when one expected cell or more $<5$.

Unpaired t-test was used to compare two groups as regard quantitative variable in parametric data ( $\mathrm{SD}<50 \%$ mean). Mann Whitney test was used instead of unpaired t-test in non-parametric data (SD $>50 \%$ mean).

\section{Results:}

The study included 60 patients with cancer colon (30 in each group), all patients had there operative management done and completed the follow-up period.

An analysis of the preoperative characteristics (age, gender, associated comorbidities, BMI, ASA score and the site of the colonic lesion) of both open and laparoscopic groups was done at first to make sure that they did not affect the outcomes of the study. The analysis had shown that there was no statistically significant difference between the two groups regarding the preoperative characteristics. The preoperative characteristics of the patients in both groups are shown in Table (1).

The operation was carried using the open 
approach in group A and the laparoscopic approach in group B. All laparoscopic cases were completed without conversion. There were no intraoperative visceral injuries in all cases. Analysis of the intraoperative parameters between both groups had shown that there was a statistically significant difference between both groups regarding the operative time with open times being shorter than the laparoscopic ones (45-60 minutes). At same time, there was no statistically significant difference between both groups regarding the intraoperative blood loss and need for transfusion. Tables $(2,3)$ shows the type of operative management and the results of intraoperative parameters for each group.

Analysis of the postoperative parameters was done. There was a statically significant difference between both groups regarding the overall postoperative complication rate. Analysis of the individual complication types showed a highly significant difference in the rate of wound related complications (infection and dehiscence) in the favor of laparoscopic group. At the same time, there was no statistically significant difference between both groups regarding the rest of complication types (leakage and chest infection). There was no statistically significant difference between both groups regarding the period of postoperative ileus and the time needed to achieve full oral intake. There was a statistically significant difference between both groups regarding the need of postoperative analgesia (in favor of laparoscopic group), and there was a highly significant difference between both groups regarding the period of hospital stay (in favor of laparoscopic group). Regarding the oncological results, resection free margins were achieved in all cases of both groups and there was no detectable cases of recurrence in both groups through the study. There was no statistically significant difference between both groups regarding the number of resected lymph nodes. Postoperative parameters are shown in Table (4).

\section{Discussion:}

Since its introduction, laparoscopic colorectal surgery, started to gain acceptance and it is gradually becoming the preferable approach for performing colonic resections in many centers. ${ }^{9}$ However, despite the theoretical advantages of laparoscopic surgery, it is still not considered the standard treatment for colorectal cancer patients due to technical limitations or characteristics of the patients that may affect short and longterm outcomes. ${ }^{10}$ This had made the adoption of laparoscopic colorectal surgery as the standard approach under many investigation and trials. Our study aims to address the question if laparoscopic approach can be used as standard operative approach for colonic cancer in our hospital.

Our study included only patients who are candidate for both approaches. It is well documented that some patients are not suitable for the laparoscopic approach (e.g. those with extensive intraabdominal adhesions and those with contraindications for insufflation), ${ }^{11}$ and eliminating them from the study helps to avoid any bias in the study group, which may affect the results. The statistical analysis of our study groups revealed no difference regarding the preoperative characteristics of the study groups, this also makes the study results more accurate and representative.

Regarding the operative parameters, we found no significant difference between open and laparoscopic groups regarding intraoperative blood loss or requirement of blood transfusion. The available literature revealed that laparoscopic colectomy is associated with the same or less intraoperative blood loss than open surgery. ${ }^{12}$ The operative time recorded in the laparoscopic group was significantly longer than in the open group. Most published studies had reported the same trend although recent studies had reported no difference or a less significant difference, mostly due to the growing experience and familiarity with the technique. ${ }^{13,14}$

Regarding the postoperative outcomes, our study showed a significant difference in postoperative complications in favor of laparoscopic group mainly due to the increase in wound related complications, although there was no difference in other types of complications. Regarding recovery, there was shorter hospital stay mainly due to less need 
for analgesia and less wound complications in the laparoscopic group, but there was no difference regarding the period of ileus or time taken to achieve full oral intake. These results are consistent with the published literature which had highlighted that laparoscopic colectomy is associated with less post-operative pain, earlier resumption of normal diet, shorter hospitalstay and better overall recovery. ${ }^{15}$ Oncological outcomes were comparable between both groups, tumor free resection was achieved in all cases, there were no recorded cases of recurrence and no difference in number in harvested lymph nodes between both groups. The same results were shown previously in literature which stated that laparoscopic colectomy achieved a comparable result to open colectomy regarding the outcomes. ${ }^{16}$

The results of our study shows that laparoscopic colectomy has short-term results that are comparable or better to open colectomy in cases of cancer colon. However, our study did not include cost analysis, which needs to be investigated, and leaves a lot to be addressed regarding the implementation of laparoscopic colectomy in routine practice and training programs.

\section{Conclusion:}

Ourresults show that laparoscopic resection for cancer colon is safe, technically feasible and has better recovery and comparable oncological results to open colectomy. More analysis is needed to address the cost benefit, long-term results and implementation of the technique to routine practice and training.

\section{Reference}

1- Reza MM, Blasco JA, Andradas E, Cantero R, Mayol J: Systematic review of laparoscopic versus open surgery for colorectal cancer. $\mathrm{Br}$ J Surg 2006; 93(8): 921-928.

2- Jacobs M, Verdeja JC, Goldstein HS: Minimally invasive colon resection (laparoscopic colectomy). Surgical Laparoscopy \& Endoscopy 1991; 1(3): 144-150.

3- Franklin ME Jr, Ramos R, Rosenthal D, Schuessler W: Laparoscopic colonic procedures. World J Surg 1993; 17: 51-56.
4- Chapman AE, Levitt MD, Hewett P, Woods R, Sheiner H, Maddern GJ: Laparoscopicassisted resection of colorectal malignancies: A systematic review. Ann Surg. 2001; 234: 590-606.

5- Kieran JA, Curet MJ: Laparoscopic colon resection for colon cancer. J Surg Res 2004; 117: 79-91.

6- Yong L, Deane M, Monson JR, Darzi A: Systematic review of laparoscopic surgery for colorectal malignancy. Surg Endosc 2001; 15: 1431-1439.

7- Lacy AM, Garcia-Valdecasas JC, Delgado S, Castells A, Taura P, Pique JM, Visa J: Laparoscopy-assisted colectomy versus open colectomy for treatment of non-metastatic colon cancer: A randomized trial. Lancet 2002; 359(9325): 2224-2229.

8- Kuntz C, Wunsch A, Rosch R, Autschbach F, Windeler J, Herfarth C: Shortand long-term results after laparoscopic vs conventional colon resection in a tumor-bearing small animal model. Surgical endoscopy 2000; 14(6): 561-567.

9- Biondi A, Grosso G, Mistretta A, Marventano S, Toscano C, Gruttadauria S, Basile F: Laparoscopic-assisted versus open surgery for colorectal cancer: Short-and longterm outcomes comparison. Journal of Laparoendoscopic \& Advanced Surgical Techniques Part A. 2013, 23(1): 1-7.

10- Vacante M, D’Agata V, Motta M, et al: Centenarians and supercentenarians: A black swan. Emerging social, medical and surgical problems. BMC Surgery 2012; 12(Suppl 1):S36.

11- Guillou PJ, Quirke P, Thorpe H, Walker J, Jayne DG, Smith AM, et al: Shortterm endpoints of conventional versus laparoscopic-assisted surgery in patients with colorectal cancer (MRC CLASICC trial): Multicenter, randomized controlled trial. Lancet 2005; 365: 1718-1726.

12- TrastulliS, Cirocchi R, Listorti C, CavaliereD, Avenia N, Gulla N, Giustozzi G, Sciannameo F, Noya G, Boselli C: Laparoscopic vs open resection for rectal cancer: A meta-analysis of randomized clinical trials. Colorectal disease. The Official Journal of The Association of Coloproctology of Great Britain and Ireland 2012; 14(6): e277-296.

Kye BH, Kim JG, Cho HM, Kim HJ, Suh YJ, Chun CS: Learning curves in laparoscopic right-sided colon cancer surgery: A comparison of first generation colorectal 
surgeon to advance laparoscopically trained surgeon. Journal of Laparoendoscopic \& Advanced Surgical Techniques Part A. 2011; 21(9): 789-796.

13- Miskovic D, Ni M, Wyles SM, Tekkis P, Hanna GB: Learning curve and case selection in laparoscopic colorectal surgery: Systematic review and international multicenter analysis of 4852 cases. Diseases of the Colon and Rectum. 2012; 55(12): 1300-1310.

14- Sun J, Jiang T, Qiu Z, Cen G, Cao J, Huang K, Pu Y, Liang H, Huang R, Chen
S: Short-term and medium-term clinical outcomes of laparoscopic assisted and open surgery for colorectal cancer: A single center retrospective case-control study. BMC Gastroenterology 2011; 11: 85.

15- Fleshman J, Sargent DJ, Green E, Anvari M, Stryker SJ, Beart RW, Hellinger M, Flanagan $\mathrm{R}$, Peters W, Nelson $\mathrm{H}$ : Laparoscopic colectomy for cancer is not inferior to open surgery based on 5-year data from the COST Study Group trial. Annals of Surgery 2007; 246(4): 655-662, discussion 662-654. 